\title{
The 2011-2020 Trends of Data-Driven Approaches in Medical Informatics for Active Pharmacovigilance
}

\author{
Hyunah Shin ${ }^{1}$, Jaehun Cha ${ }^{1}{ }^{1}$, Chungchun Lee ${ }^{1}$, Hyejin Song ${ }^{2}$, Hyuntae Jeong ${ }^{2}$, Jong-Yeup Kim ${ }^{1,3, *(D)}$ \\ and Suehyun Lee ${ }^{1,3, *}$ \\ 1 Health Care Data Science Center, Konyang University Hospital, Daejeon 35365, Korea; \\ hah1286@kyuh.ac.kr (H.S.); jaetyart@kyuh.ac.kr (J.C.); lcc91@kyuh.ac.kr (C.L.) \\ 2 Department of Biomedical Engineering, College of Medical Engineering, Konyang University, \\ Daejeon 35365, Korea; 18616029@konyang.ac.kr (H.S.); 18616059@konyang.ac.kr (H.J.) \\ 3 Department of Biomedical Informatics, College of Medicine, Konyang University, Daejeon 35365, Korea \\ * Correspondence: jykim@kyuh.ac.kr (J.-Y.K.); shleemedi@kyuh.ac.kr (S.L.); Tel.: +82-10-8805-1002 (J.-Y.K.); \\ +82-10-9012-9364 (S.L.)
}

check for updates

Citation: Shin, H.; Cha, J.; Lee, C.; Song, H.; Jeong, H.; Kim, J.-Y.; Lee, S. The 2011-2020 Trends of Data-Driven Approaches in Medical Informatics for Active Pharmacovigilance. Appl. Sci. 2021, 11, 2249. https:// doi.org/10.3390/app11052249

Academic Editor: In Young Choi

Received: 25 January 2021

Accepted: 26 February 2021

Published: 4 March 2021

Publisher's Note: MDPI stays neutral with regard to jurisdictional claims in published maps and institutional affiliations.

Copyright: (c) 2021 by the authors. Licensee MDPI, Basel, Switzerland. This article is an open access article distributed under the terms and conditions of the Creative Commons Attribution (CC BY) license (https:// creativecommons.org/licenses/by/ $4.0 /)$.

\begin{abstract}
Pharmacovigilance, the scientific discipline pertaining to drug safety, has been studied extensively and is progressing continuously. In this field, medical informatics techniques and interpretation play important roles, and appropriate approaches are required. In this study, we investigated and analyzed the trends of pharmacovigilance systems, especially the data collection, detection, assessment, and monitoring processes. We used PubMed to collect papers on pharmacovigilance published over the past 10 years, and analyzed a total of 40 significant papers to determine the characteristics of the databases and data analysis methods used to identify drug safety indicators. Through systematic reviews, we identified the difficulty of standardizing data and terminology and establishing an adverse drug reactions (ADR) evaluation system in pharmacovigilance, and their corresponding implications. We found that appropriate methods and guidelines for active pharmacovigilance using medical big data are still required and should continue to be developed.
\end{abstract}

Keywords: systematic review; data-driven approach; pharmacovigilance; medical big data; adverse drug reaction; medical informatics

\section{Introduction}

Pharmacovigilance is the pharmacological science pertaining to the collection, detection, assessment, monitoring, and prevention of adverse events related to drug safety issues [1]. Adverse drug reactions (ADRs) are mostly caused by the pharmacological action of drugs and factors such as drug-drug and drug-food interactions, drug errors, allergies, and metabolism [2,3]. ADR is a leading cause of death in the United States; moreover, ADR causes a larger number of deaths than lung disease, diabetes, HIV / AIDS, and pneumonia [4,5]. Therefore, it is important to identify all possible drug reactions with the aid of pharmacovigilance [3].

Even if the efficacy and safety of a drug are verified through clinical trials, it may still be necessary to conduct post-marketing surveillance because clinical trials clearly possess limitations [6]. In actuality, prescription and dosage errors could arise, and issues could exist in medication compliance as well. Additionally, whereas patients suffering chronic diseases require lifelong drug intake, most clinical trials have only a fixed period. ADRs could occur if a drug is administered for long periods. In other words, post-marketing surveillance is becoming increasingly important, requiring pharmacovigilance to be performed [6].

Pharmacovigilance utilizes various big data sources, including spontaneous reporting systems (SRS), medical literature, electronic health records (EHR), and social media [7-9]. Pharmacovigilance comprises two different systems, namely, passive surveillance and 
active surveillance systems [10,11]. Passive surveillance relies on SRS from medical personnel and patients; this case possesses a severe limitation of underreporting, i.e., less than $1 \%$ of ADRs are reported [12]. In active surveillance, various databases based on EHRs, which contain detailed patient information, could be constructed [13]. Additionally, active surveillance can be used to identify new drug safety signals or verify the indicators identified through passive surveillance [11]. Immediate monitoring of ADR, improvement of efficacy, and exploration using various natural language processing (NLP) technologies are indispensable from the perspective of medical informatics [14,15]. Therefore, a systematic medical informatics approach is required to apply appropriate techniques to pharmacovigilance systems.

Pharmacovigilance, which is a dynamic discipline, has evolved significantly since the 1972 World Health Organization (WHO) technical report [16]. Since then, various studies related directly to patient safety have been conducted and many related review papers have been published.

This work reviews the entire range of pharmacovigilance studies conducted over the last 10 years and investigates the overall trends. The main results and limitations of these studies are summarized by categorizing them into sections ranging from collection to monitoring. Finally, we emphasize the role and necessity of medical informatics in active pharmacovigilance and pharmacovigilance platforms.

\section{Published Trends}

We used the PubMed database of publications in life sciences and biomedical research from the United States National Library of Medicine (NLM) to examine the overall trends in pharmacovigilance research [17]. We extracted papers published from 1 January 2011 to 31 December 2020 using keywords that describe and include all fields of "Pharmacovigilance", "Adverse drug reaction", and "Pharmacovigilance systems (Collection, Detection, Assessment, Monitoring)", as shown in Table 1. A total of 3322 related papers, composed of journal articles, meta-analyses, reviews, systematic reviews, and observational studies, have been published over the past 10 years. We excluded papers based on their title and abstract, and manually reviewed the criteria for improper subject design, as shown in Figure 1. Finally, 10 papers each were selected for collection, detection, assessment, and monitoring.

Table 1. Medical Subject Heading (MeSH) terms used in reviewing the published literature related to pharmacovigilance (if no "MeSH" term exists, search for "All Fields").

"Pharmacovigilance" [MeSH] OR "Pharmacovigilance" [All Fields] OR "PV" [All Fields]

AND

"Drug-Related Side Effects and Adverse Reactions" [MeSH] OR "ADR" [All Fields] OR "ADRs"

[All Fields] OR "ADE" [All Fields] OR "ADEs" [All Fields] OR "AE" [All Fields] OR "AEs" [All Fields] OR

"Drug-induced" [All Fields] AND

"Collection" [All Fields] OR “Detection" [All Fields] OR

"Assessment" [All Fields] OR "Monitoring" [All Fields]

PV: Pharmacovigilance, ADR: Adverse drug reaction, ADE: Adverse drug event, AE: Adverse event. 


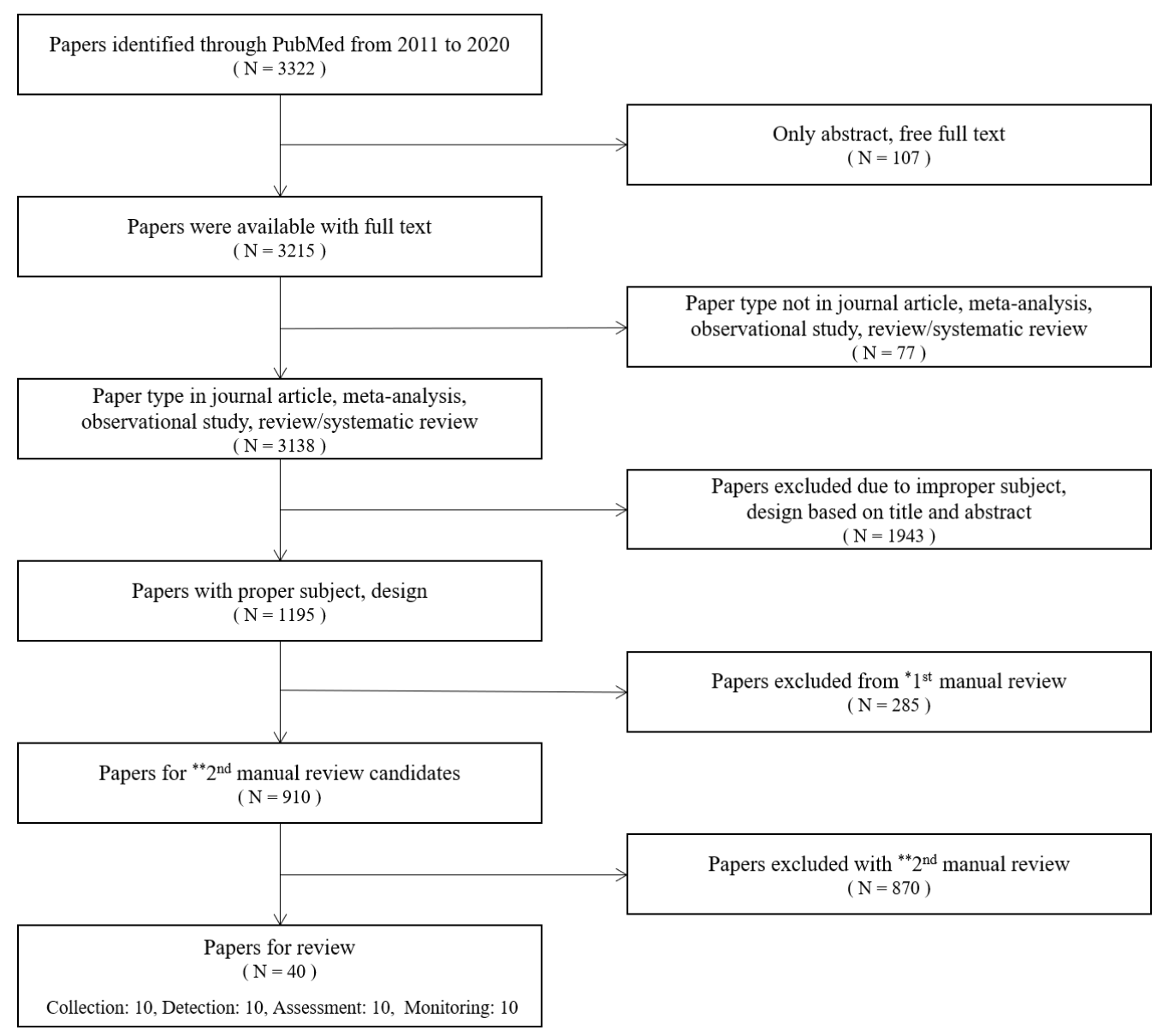

Figure 1. Flowchart depicting the paper selection process. * 1st manual review: animal experiment, not drug-induced, clinical effect; ${ }^{* *}$ 2nd manual review: diversity and authenticity of databases, methods.

\section{Pharmacovigilance Systems}

We summarized and discussed the trends observed for each pharmacovigilance system that collects, detects, assesses, and monitors the adverse events related to drug safety issues [1]. For an overall understanding of the systems, we expressed the detection methods used in representative databases, standard terms in assessment, and activities performed in monitoring. Then, we included the keywords and representative terms for each system, as shown in Figure 2.

\subsection{Data Collection}

Collection is the key component of an active surveillance system that accesses and extracts data from pharmacovigilance-related databases. It is important to use the appropriate data for this study. We identified significant drug safety indicators using the databases. Drug safety indicators can be found from various databases, such as EHRs, claims data, registries, spontaneous reports, and the literature [18]. Based on studies that used various databases, we classified the databases into nine categories: EHRs, SRSs, structured product labeling (SPL), drug information databases, claims databases, genetics and biochemical databases, bibliographic databases, and social media data. The classification criteria determined whether the search involved clinical institution data, spontaneous reports, or heterogeneous data from the literature, and determined how the overall composition of the drugs was analyzed. We selected and reviewed 10 papers [19-28] that investigated a diverse range of databases, and summarized the data, objectives, and methods used in each study (Table 2). 


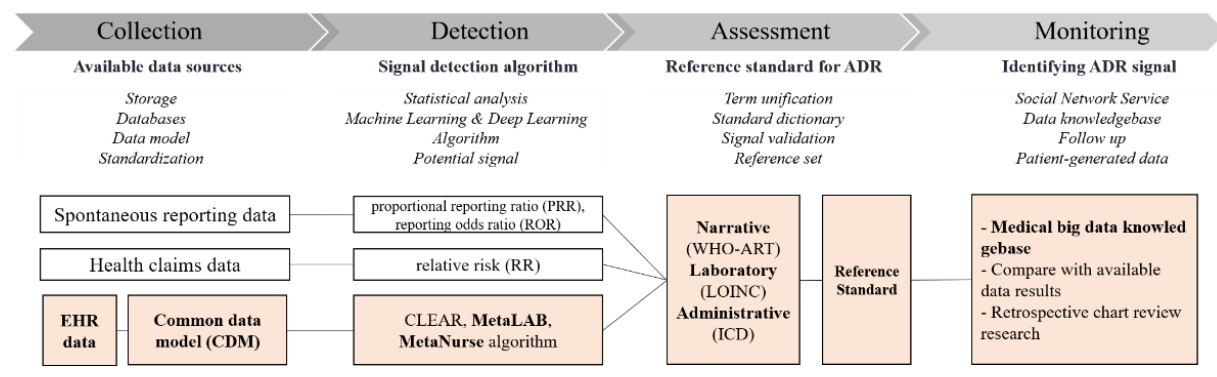

Figure 2. Collection, detection, assessment, and monitoring processes in pharmacovigilance systems.

Table 2. Selected papers and their sources of data for determining drug safety signals.

\begin{tabular}{|c|c|c|c|}
\hline Author(s) & Data & Objective & Method(s) \\
\hline Olsson et al. [19] & 1. SRSs & $\begin{array}{c}\text { Legislation and regulatory } \\
\text { framework, as well as financial } \\
\text { support to build pharmacovigilance } \\
\text { systems are needed }\end{array}$ & - \\
\hline Tan et al. [20] & $\begin{array}{c}\text { 1. SRSs } \\
\text { 2. Drug information databases } \\
\text { 3. ADE databases } \\
\text { 4. Genetics and biochemical } \\
\text { databases } \\
\text { 5. Bibliographic databases }\end{array}$ & $\begin{array}{l}\text { Presenting the current status of the } \\
\text { clinical decision support system } \\
\text { (CDSS) }\end{array}$ & $\begin{array}{l}\text { 1. Text mining } \\
\text { 2. NLP } \\
\text { 3. Machine learning } \\
\text { 4. Deep learning } \\
\text { 5. Statistical analysis }\end{array}$ \\
\hline Faillie et al. [21] & $\begin{array}{l}\text { 1. SRSs } \\
\text { 2. Drug information databases } \\
\text { 3. Genetics and biochemical } \\
\text { databases }\end{array}$ & $\begin{array}{l}\text { Discuss the contribution of } \\
\text { pharmacoepidemiology to } \\
\text { pharmacovigilance }\end{array}$ & 1. Statistical analysis \\
\hline
\end{tabular}

Build a semantic resource based on formal description logic to aid the Souvignet et al. [22] 1. Drug information databases generation of on-demand custom groupings by appropriately selecting 1. Statistical analysis terms: OntoADR

\begin{tabular}{|c|c|c|c|}
\hline Malec et al. [23] & $\begin{array}{l}\text { 1. EHRs } \\
\text { 2. Drug information databases } \\
\text { 3. Bibliographic databases }\end{array}$ & $\begin{array}{l}\text { Presenting methods to discover } \\
\text { confounding variables based on } \\
\text { scalable literature }\end{array}$ & $\begin{array}{l}\text { 1. NLP } \\
\text { 2. Statistical analysis }\end{array}$ \\
\hline Trifirò et al. [24] & $\begin{array}{l}\text { 1. SRSs } \\
\text { 2. Drug information databases } \\
\text { 3. ADE databases }\end{array}$ & $\begin{array}{l}\text { Discussion on the use of big data after } \\
\text { drug safety evaluation }\end{array}$ & $\begin{array}{c}\text { 1. NLP } \\
\text { 2. Machine learning }\end{array}$ \\
\hline $\begin{array}{l}\text { The Knowledge Base } \\
\text { workgroup of the } \\
\text { Observational Health Data } \\
\text { Sciences and Informatics } \\
\text { (OHDSI) collaborative. } \\
\text { [25] }\end{array}$ & $\begin{array}{c}\text { 1. EHRs } \\
\text { 2. SRSs } \\
\text { 3. SPLs } \\
\text { 4. Genetics and biochemical } \\
\text { databases } \\
\text { 5. Bibliographic databases }\end{array}$ & $\begin{array}{l}\text { Introduce the structure and } \\
\text { functionality of the Largescale } \\
\text { Adverse Effects Related to Treatment } \\
\text { Evidence Standardization (LAERTES) }\end{array}$ & $\begin{array}{l}\text { 1. NLP } \\
\text { 2. Machine learning } \\
\text { 3. Statistical analysis }\end{array}$ \\
\hline Fornasier et al. [26] & $\begin{array}{l}\text { 1. SRSs } \\
\text { 2. ADE databases }\end{array}$ & $\begin{array}{l}\text { Understand the important role of } \\
\text { pharmacovigilance as a } \\
\text { historical phase }\end{array}$ & - \\
\hline Choi et al. [27] & $\begin{array}{l}\text { 1. EHRs } \\
\text { 2. Genetics and biochemical } \\
\text { databases }\end{array}$ & $\begin{array}{l}\text { Future personalized therapy } \\
\text { considering ADEs }\end{array}$ & 1. Statistical analysis \\
\hline Alomar et al. [28] & 1. SRSs & $\begin{array}{l}\text { The importance of policy framework } \\
\text { in relation to pharmacovigilance is } \\
\text { discussed in detail }\end{array}$ & $\begin{array}{l}\text { 1. Machine learning } \\
\text { 2. Statistical analysis }\end{array}$ \\
\hline
\end{tabular}

SRSs: spontaneous reporting systems, NLP: natural language processing, ADE: adverse drug event, EHRs: electronic health records, SPLs: structured product labels. 
Bihan et al. [29] published the most recent review article on different pharmacovigilance databases, including VigiBase of the WHO [30], EudraVigilance of the European Medicines Agency (EMA) [31], the FDA Adverse Event Reporting System (FAERS) of the United States Food and Drug Administration [32], and the French pharmacovigilance database (FPDB) [33]. Additionally, databases are available for nationally managed systems, clinical institution data, drug information, and from the literature; for example, Sentinel [34], Exploring and Understanding Adverse Drug Reactions (EU-ADR) [35], EHR [36], DrugBank [37], and MEDLINE [38].

\subsection{ADR Detection for Pharmacovigilance}

In detection, advanced methods are available to find drug safety indicators using the databases identified through collection. These indicators can be used to detect drug-related problems, typically ADRs, adverse drug events (ADEs), or drug-drug interactions [39]. To find indicators from EHR data, the measurement results or prescription history (including patient information) can be used along with drug information or related label information for other registries. The methods to be used differ depending on the database and can be selected by comparing their performance appropriately. Thus, we categorized the detection methods into five types to organize tables with relationships between the databases and methods. Each method involves statistical analyses (descriptive analysis, cohort study, computational analysis, disproportionality analysis), text mining, NLP, machine learning, and deep learning. Initially, if statistical analysis was dominant, then NLP and machine learning techniques were applied as developments in computer technology.

As shown in Table 3 [40-49], some studies have examined drug-related correlations by using computational methods [42,47] and survival analysis [40,46] with statistical approaches. These studies analyzed the drug exposure groups and non-exposure groups through comparison. As the first step of detection algorithms or methods, most studies are preprocessed through data mining or NLPs [44,47,49]. With the active development of artificial intelligence methods in big data analysis, various machine learning $[44,45,47]$ or deep learning techniques [48] have been applied to pharmacovigilance, and more studies have integrated and analyzed two or more databases rather than only a single database $[40,42,43,45,47-49]$. Potential drug safety indicators could be detected using various methodologies and approaches.

\subsection{Assessment for $A D R$}

Assessment through clinical or scientific interpretation is a requirement to evaluate drug safety indicators. To prepare an evaluation system and expand the reference standard, a systematic strategy is required. Reference sets used commonly in pharmacovigilance include side effect resource (SIDER) [50], The Observational Medical Outcomes Partnership (OMOP) [51], and EU-ADR [35]. These references set the standards for known drug-related information that provide positive and negative controls based on drug safety indicators and ADR. Different terminology systems exist in pharmacovigilance (e.g., MedDRA and WHO Adverse Reactions Terminology (WHO-ART)); thus, unification and mapping between the terms must be performed to develop reference standards. 
Table 3. List of papers for ADR detection methods and algorithms.

\begin{tabular}{|c|c|c|c|}
\hline Author & Data & Objective & Methods \\
\hline McCarren et al. [40] & $\begin{array}{l}\text { 1. EHRs } \\
\text { 2. Claims databases }\end{array}$ & $\begin{array}{l}\text { Detailed study on } \\
\text { antipsychotics prescribed to } \\
\text { evaluate the effects of } \\
\text { risperidone }\end{array}$ & 1. Statistical analysis \\
\hline Sun et al. [41] & 1. EHRs & $\begin{array}{c}\text { Assess the utility of } \\
\text { unplanned medication } \\
\text { discontinuation as a signal for } \\
\text { possible ADEs in children and } \\
\text { young people }\end{array}$ & 1. Statistical analysis \\
\hline Dupuch and Grabar [42] & $\begin{array}{c}\text { 1. SRSs } \\
\text { 2. Drug information databases }\end{array}$ & $\begin{array}{l}\text { Propose an automatic method } \\
\text { to assist in the creation of } \\
\text { Standardized MedDRA } \\
\text { Queries (SMQs) using the } \\
\text { clustering of terms }\end{array}$ & 1. Statistical analysis \\
\hline Pacurariu et al. [43] & $\begin{array}{l}\text { 1. SRSs } \\
\text { 2. ADE databases } \\
\text { 3. Bibliographic databases }\end{array}$ & $\begin{array}{l}\text { Investigate the potential of } \\
\text { EHRs to be used alongside } \\
\text { SRSs, to improve signal } \\
\text { detection }\end{array}$ & 1. Statistical analysis \\
\hline Usui et al. [44] & 1. EHRs & $\begin{array}{l}\text { Develop a method to extract } \\
\text { and standardize patient } \\
\text { complaints from electronic } \\
\text { medication history data } \\
\text { (EMHD) }\end{array}$ & $\begin{array}{c}\text { 1. NLP } \\
\text { 2. Machine learning }\end{array}$ \\
\hline Thompson et al. [45] & 1. Bibliographic databases & $\begin{array}{l}\text { Describe the development } \\
\text { process of Pharmacovigilance } \\
\text { Entity Drug Annotation } \\
\text { (PHAEDRA) with annotation }\end{array}$ & $\begin{array}{l}\text { 1. Text mining } \\
\text { 2. Machine learning }\end{array}$ \\
\hline
\end{tabular}

Characterize the reported

ADE onsets registered with

$\begin{array}{lll}\text { Kiguba et al. [46] } & \text { 1. SRSs } & \begin{array}{c}\text { VigiBase and describe an } \\ \text { analytical approach for } \\ \text { patients receiving }\end{array}\end{array}$
antiretroviral therapy

\begin{tabular}{|c|c|c|c|}
\hline Ventola [47] & $\begin{array}{l}\text { 1. EHRs } \\
\text { 2. SRSs } \\
\text { 3. ADE databases } \\
\text { 4. Bibliographic databases } \\
\text { 5. Social media }\end{array}$ & $\begin{array}{l}\text { Discuss data mining for big } \\
\text { data and pharmacovigilance }\end{array}$ & $\begin{array}{l}\text { 1. Text mining } \\
\text { 2. NLP } \\
\text { 3. Machine learning } \\
\text { 4. Statistical analysis }\end{array}$ \\
\hline Wang et al. [48] & $\begin{array}{l}\text { 1. ADE databases } \\
\text { 2. Bibliographic databases }\end{array}$ & $\begin{array}{l}\text { Identify a method to detect } \\
\text { potential ADEs of drugs } \\
\text { automatically using a deep } \\
\text { neural network (DNN) }\end{array}$ & $\begin{array}{l}\text { 1. Deep learning } \\
\text { 2. Statistical analysis }\end{array}$ \\
\hline Yu et al. [49] & $\begin{array}{l}\text { 1. ADE databases } \\
\text { 2. Bibliographic databases }\end{array}$ & $\begin{array}{l}\text { Develop a new irAE signal } \\
\text { detection and filtering } \\
\text { framework concerning six } \\
\text { FDA-approved immune } \\
\text { checkpoint inhibitor drugs }\end{array}$ & $\begin{array}{l}\text { 1. Text mining } \\
\text { 2. Statistical analysis }\end{array}$ \\
\hline
\end{tabular}

EHRs: electronic health records, SRSs: spontaneous reporting systems, ADE: adverse drug event, NLP: natural language processing, FDA: The United States Food and Drug Administration.

Table 4 summarizes the related papers and their properties [52-61]. Some studies approached the signals in specific diseases in more detail, such as pancreatitis [52] and liver injury $[53,54,58]$, and used EHR [36] or observational data that contain more patient information than other databases. Additionally, studies that proposed the refer- 
ence standards to identify drug-induced ADRs did literature analysis used bibliographic databases $[53,54,56,57]$. We found that experts worked manually to determine the signals and produce results [53]. In particular, Oosterhuis et al. [60] developed a causality documentation (CausDOC) tool that combines algorithms and expert judgment to provide nine relevant structured questions to assess the causality of ADRs.

Table 4. List of papers for assessing ADR signals and developing reference sets.

\begin{tabular}{|c|c|c|c|}
\hline Author & Data & Objective & Methods \\
\hline Vilar et al. [52] & 1. EHRs & $\begin{array}{c}\text { Develop molecular } \\
\text { fingerprint-based models } \\
\text { (MFBMs) to strengthen ADE } \\
\text { signals generated from EHR } \\
\text { data }\end{array}$ & $\begin{array}{l}\text { 1. NLP } \\
\text { 2. Statistical analysis }\end{array}$ \\
\hline Coloma et al. [53] & $\begin{array}{l}\text { 1. EHRs } \\
\text { 2. SRSs } \\
\text { 3. ADE databases } \\
\text { 4. Bibliographic databases }\end{array}$ & $\begin{array}{c}\text { Develop and evaluate } \\
\text { methods in the EU-ADR } \\
\text { project }\end{array}$ & 1. Statistical analysis \\
\hline Crepin et al. [54] & $\begin{array}{l}\text { 1. SRSs } \\
\text { 2. Bibliographic databases } \\
\text { 3. ADE databases }\end{array}$ & $\begin{array}{c}\text { Review similar reports in } \\
\text { pharmacovigilance databases }\end{array}$ & 1. Statistical analysis \\
\hline Benkirane et al. [55] & 1. SRSs & $\begin{array}{l}\text { Present } P \text { method }(\mathrm{PM}) \text { and } \\
\text { evaluate its inter-rater } \\
\text { reliability }\end{array}$ & 1. Statistical analysis \\
\hline Winnenburg and Shah [56] & 1. Bibliographic databases & $\begin{array}{c}\text { Evaluate how to improve } \\
\text { detection of side effects in } \\
\text { MeSH }\end{array}$ & $\begin{array}{l}\text { 1. NLP } \\
\text { 2. Statistical analysis }\end{array}$ \\
\hline Batel-Marques et al. [57] & 1. Bibliographic databases & $\begin{array}{l}\text { Assess ADEs and their } \\
\text { associated costs }\end{array}$ & 1. Statistical analysis \\
\hline Scalfaro et al. [58] & $\begin{array}{l}\text { 1. EHRs } \\
\text { 2. SRSs }\end{array}$ & $\begin{array}{l}\text { Evaluate the performance of } \\
\text { Pharmacovigilance-Roussel } \\
\text { Uclaf Causality Assessment } \\
\text { Method (PV-RUCAM) }\end{array}$ & 1. Statistical analysis \\
\hline Caster et al. [59] & $\begin{array}{l}\text { 1. SRSs } \\
\text { 2. Social media }\end{array}$ & $\begin{array}{l}\text { Assess the performance of } \\
\text { statistical signal detection } \\
\text { algorithms established in } \\
\text { social media data }\end{array}$ & 1. Statistical analysis \\
\hline Oosterhuis et al. [60] & $\begin{array}{l}\text { 1. Drug information databases } \\
\text { 2. ADE databases }\end{array}$ & $\begin{array}{c}\text { Test the validity and reliability } \\
\text { of the causality } \\
\text { documentation (CausDoc) } \\
\text { tool }\end{array}$ & 1. Statistical analysis \\
\hline Lee et al. [61] & $\begin{array}{l}\text { 1. EHRs } \\
\text { 2. ADE databases }\end{array}$ & $\begin{array}{c}\text { Development for } \\
\text { pharmacovigilance to detect } \\
\text { and evaluate ADE signals } \\
\text { based on multicenter EHR }\end{array}$ & 1. Statistical analysis \\
\hline
\end{tabular}

EHRs: electronic health records, ADE: adverse drug event, NLP: natural language processing, SRSs: spontaneous reporting systems, EU-ADR: Exploring and Understanding Adverse Drug Reactions, MeSH: Medical Subject Headings.

\subsection{ADR Monitoring for Patient Safety}

Monitoring involves the continuous follow-up and safety management of a patient's condition, and can be said to be the ultimate purpose of pharmacovigilance. Table 4 lists the studies on monitoring [62-71] in chronological order. We could investigate early studies conducted on a large-scale project basis [62,66]. From 2009 to 2013, Pal et al. [66] carried out the Monitoring Medicines (MM) Project that consisted of 11 consortium partners. Mobile 
applications have also been developed (e.g., MedWatcher) to improve the spontaneous reporting of patients and the management of reports with patient information [68].

With the activation of social network systems (SNS), SNS data (e.g., Twitter and Facebook) have been analyzed as additional study data $[69,70]$. Table 5 shows that recent studies use SRSs and social media data as the main analysis data sources and use EHR data or ADE databases as supplemental data [68-71]. In addition to these recent trends, patient-generated data can be collected through health care services or wearable devices, which requires more diverse monitoring methods and protocols.

Table 5. List of papers for monitoring ADR and managing patient safety.

\begin{tabular}{|c|c|c|c|}
\hline Author & Data & Objective & Methods \\
\hline Blake et al. [62] & $\begin{array}{l}\text { 1. Drug information databases } \\
\text { 2. ADE databases }\end{array}$ & $\begin{array}{l}\text { Provide a broad estimate of the need } \\
\text { for pharmacoepidemiologic resources } \\
\text { in the European Union (EU) }\end{array}$ & 1. Statistical analysis \\
\hline Ruggiero et al. [63] & 1. SRSs & $\begin{array}{l}\text { Systematic collection of more } \\
\text { thorough data on the safety of } \\
\text { atomoxetine and methylphenidate in } \\
\text { pediatric settings }\end{array}$ & 1. Statistical analysis \\
\hline Härmark et al. [64] & $\begin{array}{l}\text { 1. Genetics and biochemical } \\
\text { databases }\end{array}$ & $\begin{array}{l}\text { Compare the LIM diabetes } \\
\text { population with an external diabetes } \\
\text { reference population on } \\
\text { characteristics that may influence the } \\
\text { patient's susceptibility for ADEs }\end{array}$ & 1. Statistical analysis \\
\hline Liu et al. [65] & 1. EHRs & $\begin{array}{c}\text { Examine the use of retrospective } \\
\text { medication orders and inpatient } \\
\text { laboratory results documented in } \\
\text { the EHR }\end{array}$ & 1. Statistical analysis \\
\hline Pal et al. [66] & 1. SRSs & $\begin{array}{l}\text { Support and strengthen consumer } \\
\text { reporting of ADEs and develop } \\
\text { methods to complement } \\
\text { spontaneous reporting }\end{array}$ & 1. Statistical analysis \\
\hline Layton and Shakir. [67] & 1. EHRs & $\begin{array}{l}\text { Monitor, research, and add missing } \\
\text { information before drug marketing }\end{array}$ & 1. Statistical analysis \\
\hline Bahk et al. [68] & $\begin{array}{l}\text { 1. SRSs } \\
\text { 2. ADE databases }\end{array}$ & $\begin{array}{c}\text { Evaluate the quality of data collected } \\
\text { through a MedWatcher }\end{array}$ & 1. Statistical analysis \\
\hline Sarker et al. [69] & 1. Bibliographic databases & $\begin{array}{c}\text { Perform a methodical review to } \\
\text { characterize the different approaches } \\
\text { to ADEs detection/extraction from } \\
\text { social media }\end{array}$ & $\begin{array}{l}\text { 1. Text mining } \\
\text { 2. NLP } \\
\text { 3. Machine learning } \\
\text { 4. Statistical analysis }\end{array}$ \\
\hline Pierce et al. [70] & $\begin{array}{l}\text { 1. SRSs } \\
\text { 2. Social media }\end{array}$ & $\begin{array}{l}\text { Examine whether specific } \\
\text { product-adverse event pairs were } \\
\text { reported via social media before } \\
\text { being reported to FAERS }\end{array}$ & $\begin{array}{l}\text { 1. Machine learning } \\
\text { 2. Statistical analysis }\end{array}$ \\
\hline Irving et al. [71] & $\begin{array}{l}\text { 1. EHRs } \\
\text { 2. SRSs }\end{array}$ & $\begin{array}{l}\text { Describe the impact of design choices } \\
\text { on the practical implementation of } \\
\text { pragmatic trials }\end{array}$ & 1. Statistical analysis \\
\hline
\end{tabular}

ADE: adverse drug event, SRSs: spontaneous reporting systems, LIM: lareb intensive monitoring, EHRs: electronic health records, NLP: natural language processing, FAERS: The United States Food and Drug Administration Adverse Event Reporting System.

\section{Discussion}

Over the past 10 years, the numbers of pharmacovigilance studies have been increasing steadily. These studies have resulted in appropriate drug use regulations and guidance being issued. We found, through a literature review, that the main concerns in pharmacovigilance are the difficulty of standardizing data and terminology and establishing an 
ADR evaluation system. The databases and related websites provide mapping files or materials for terminology. However, even with expert guidance, pre-processing the data for practical analysis is time-intensive; many cases exist where a clinician or a pharmacist has to process the data manually. Therefore, reference standards could serve as ground truth for evaluating the ADR signals $[53,65,70]$.

Many studies have developed new detection algorithms and detected drug safety indicators, but the results rarely lead to actual drug safety management. In addition, the studies using patient data are limited to single institution data, emphasizing the necessity of multicenter studies [72-74]. Thus, a platform that can comprehensively manage and systematically access all pharmacovigilance systems is required. Such a platform can contribute to practical drug safety management by organizing the system of collection, detection, assessment, and monitoring into a new standard protocol.

For collection, the conversion and structuring of data into a common data model (CDM) format should be supported. Clinical CDM, medical images, and medical device CDM can be used in pharmacovigilance. As shown in Figure 3, data marts for each study design are also required. Based on the pharmacovigilance platform, anonymized data and analysis results from signal detection can be shared with registered researchers or institutions. Through multicenter research and meta-analysis of the results, the validity of the signals can be verified. By developing a monitoring app linked to the platform, patient conditions can be monitored and prescribed drugs can be managed to ensure patient safety.

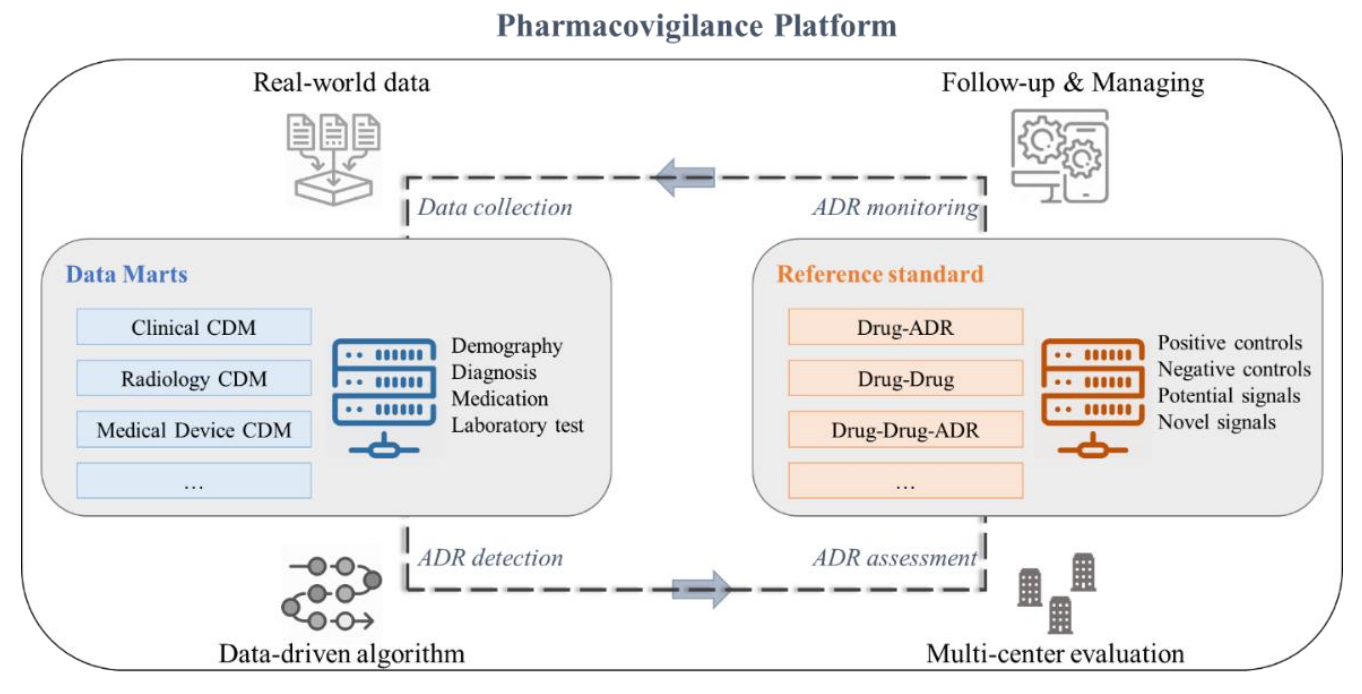

Figure 3. Feature diagram of the platform for active pharmacovigilance.

In this study, we examined the roles and importance of medical informatics in pharmacovigilance. We summarized the characteristics and results of various studies on pharmacovigilance, and identified the trends of methodology Overall, a detailed approach is required to prepare a system that can integrate and analyze big data containing plenteous information. In active pharmacovigilance, the application of the data-driven approach is expanding gradually; nevertheless, further research is required on the perspective of medical informatics.

Author Contributions: Conceptualization: J.-Y.K., S.L.; data curation: H.S. (Hyunah Shin), J.-Y.K.; formal analysis: H.S. (Hyunah Shin), J.C., C.L., H.J., H.S. (Hyejin Song). Writing-original draft: H.S. (Hyunah Shin), J.C.; writing-review and editing: H.S. (Hyunah Shin), J.C., J.-Y.K., S.L. All authors have read and agreed to the published version of the manuscript. 
Funding: This research was funded by National Research Foundation of Korea (NRF) grant funded by the Ministry of Science ICT and Future Planning (MSIP) (2018R1D1A1B07049155) and the Korea Health Technology R\&D Project through the Korea Health Industry Development Institute (KHIDI), funded by the Ministry of Health \& Welfare, Republic of Korea (grant number: HI17C2412).

Institutional Review Board Statement: Not applicable.

Informed Consent Statement: Not applicable.

Data Availability Statement: No new data were created or analyzed in this study. Data sharing is not applicable to this article.

Conflicts of Interest: The authors declare no conflict of interest with respect to the research, authorship, and/or publication of this article.

\section{References}

1. Toklu, H.Z.; Mensah, E. Why do we need pharmacists in pharmacovigilance systems? Online J. Public Health Inf. $2016,8$. [CrossRef] [PubMed]

2. Zhou, Z.; Hultgren, K.E. Complementing the us food and drug administration adverse event reporting system with adverse drug reaction reporting from social media: Comparative analysis. JMIR Public Health Surveill. 2020, 6, e19266. [CrossRef]

3. Ingle, S.S.; Bansod, A.K.; Bashir, M.S.M. Adverse drug reaction profile in Amravati region of India: A pharmacovigilance study. J. Pharm. Bioallied Sci. 2020, 12, 155-162. [CrossRef] [PubMed]

4. Institute of Medicine Committee on Quality of Health Care in America. To Err is Human: Building a Safer Health System; Kohn, L.T., Corrigan, J.M., Donaldson, M.S., Eds.; National Academies Press (US): Washington, DC, USA, 2000.

5. Preventable Adverse Drug Reactions: A Focus on Drug Interactions. Available online: https://www.fda.gov/drugs/druginteractions-labeling/preventable-adverse-drug-reactions-focus-drug-interactions (accessed on 24 December 2020).

6. Harpaz, R.; DuMochel, W.; Shah, N. Big Data and Adverse Drug Reaction Detection. Clin. Pharmacol. Ther. 2015, 99, 268-270. [CrossRef] [PubMed]

7. Zhang, P.; Wu, H.-Y.; Chiang, C.-W.; Wang, L.; Binkheder, S.; Wang, X.; Zeng, D.; Quinney, S.K.; Donglin, Z. Translational biomedical informatics and pharmacometrics approaches in the drug interactions research. CPT Pharmacomet. Syst. Pharmacol. 2018, 7, 90-102. [CrossRef]

8. Vilar, S.; Friedman, C.; Hripcsak, G. Detection of drug-drug interactions through data mining studies using clinical sources, scientific literature and social media. Briefings Bioinform. 2018, 19, 863-877. [CrossRef] [PubMed]

9. Coloma, P.M.; Trifirò, G.; Patadia, V.; Sturkenboom, M. Postmarketing safety surveillance. Drug Saf. 2013, 36, 183-197. [CrossRef]

10. Mehta, U.; Kalk, E.; Boulle, A.; Nkambule, P.; Gouws, J.; Rees, H.; Cohen, K. Pharmacovigilance: A public health priority for South Africa. S. Afr. Health Rev. 2017, 2017, 125-133. [PubMed]

11. Weaver, J.; Willy, M.; Avigan, M. Informatic tools and approaches in postmarketing pharmacovigilance used by FDA. AAPS J. 2008, 10, 35-41. [CrossRef]

12. Vohra, S.; Cvijovic, K.; Charrois, T.L.; Arnason, J.T.; Necyk, C.; Ware, M.; Rosychuk, R.J.; Boon, H.; Foster, B.C.; Jaeger, W.; et al. Study of natural health product adverse reactions (Sonar): Active surveillance of adverse events following concurrent natural health product and prescription drug use in community pharmacies. PLoS ONE 2012, 7, e45196. [CrossRef] [PubMed]

13. Zhuo, L.; Farrell, P.J.; McNair, D.; Krewski, D.; McNair, D. Statistical methods for active pharmacovigilance, with applications to diabetes drugs. J. Biopharm. Stat. 2014, 24, 856-873. [CrossRef]

14. Naidu, M.V.S.; Sushma, D.S.; Jaiswal, V.; Asha, S.; Pal, T. The role of advanced technologies supplemented with traditional methods in pharmacovigilance sciences. Recent Patents Biotechnol. 2020, 14, 1-13. [CrossRef]

15. Nikfarjam, A.; Ransohoff, J.D.; Callahan, A.; Jones, E.; Loew, B.; Kwong, B.Y.; Sarin, K.Y.; Shah, N.H. Early detection of adverse drug reactions in social health networks: A natural language processing pipeline for signal detection. JMIR Public Health Surveill. 2019, 5, e11264. [CrossRef]

16. World Health Organization. The Importance of Pharmacovigilance: Safety Monitoring of Medicinal Products; World Health Organization: Geneva, Switzerland, 2002.

17. Chen, X.; Xie, H.; Cheng, G.; Poon, L.K.M.; Leng, M.; Wang, F.L. Trends and features of the applications of natural language processing techniques for clinical trials text analysis. Appl. Sci. 2020, 10, 2157. [CrossRef]

18. Beninger, P. Pharmacovigilance: An overview. Clin. Ther. 2018, 40, 1991-2004. [CrossRef] [PubMed]

19. Olsson, S.; Pal, S.N.; Dodoo, A. Pharmacovigilance in resource-limited countries. Expert Rev. Clin. Pharmacol. 2015, 8, 449-460. [CrossRef] [PubMed]

20. Tan, Y.; Hu, Y.; Liu, X.; Yin, Z.; Chen, X.-W.; Liu, M. Improving drug safety: From adverse drug reaction knowledge discovery to clinical implementation. Methods 2016, 110, 14-25. [CrossRef]

21. Faillie, J.-L.; Montastruc, F.; Montastruc, J.-L.; Pariente, A. Pharmacoepidemiology and its input to pharmacovigilance. Therapies 2016, 71, 211-216. [CrossRef] [PubMed]

22. Souvignet, J.; Declerck, G.; Asfari, H.; Jaulent, M.-C.; Bousquet, C. OntoADR a semantic resource describing adverse drug reactions to support searching, coding, and information retrieval. J. Biomed. Inform. 2016, 63, 100-107. [CrossRef] 
23. Malec, S.A.; Wei, P.; Xu, H.; Bernstam, E.V.; Myneni, S.; Cohen, T. Literature-based discovery of confounding in observational clinical data. AMIA Annu. Symp. Proc. 2017, 2016, 1920-1929. [PubMed]

24. Trifirò, G.; Sultana, J.; Bate, A. From big data to smart data for pharmacovigilance: The role of healthcare databases and other emerging sources. Drug Saf. 2017, 41, 143-149. [CrossRef]

25. The Knowledge Base workgroup of the Observational Health Data Sciences and Informatics (OHDSI) Collaborative; Boyce, R.D. Large-scale adverse effects related to treatment evidence standardization (LAERTES): An open scalable system for linking pharmacovigilance evidence sources with clinical data. J. Biomed. Semant. 2017, 8, 11:1-11:15. [CrossRef]

26. Fornasier, G.; Francescon, S.; Leone, R.; Baldo, P. An historical overview over Pharmacovigilance. Int. J. Clin. Pharm. 2018, 40, 744-747. [CrossRef] [PubMed]

27. Choi, Y.H.; Han, C.Y.; Kim, K.S.; Kim, S.G. Future directions of pharmacovigilance studies using electronic medical recording and human genetic databases. Toxicol. Res. 2019, 35, 319-330. [CrossRef] [PubMed]

28. AlOmar, M.; Palaian, S.; Al-Tabakha, M.M. Pharmacovigilance in perspective: Drug withdrawals, data mining and policy implications. F1000Research 2019, 8, 2109. [CrossRef] [PubMed]

29. Bihan, K.; Lebrun-Vignes, B.; Funck-Brentano, C.; Salem, J.-E. Uses of pharmacovigilance databases: An overview. Therapies 2020, 75, 591-598. [CrossRef]

30. Lindquist, M. VigiBase, the WHO global ICSR database system: Basic facts. Ther. Innov. Regul. Sci. 2008, 42, 409-419. [CrossRef]

31. Blake, K.V.; Zaccaria, C.; Domergue, F.; La Mache, E.; Saint-Raymond, A.; Hidalgo-Simon, A. Comparison between paediatric and adult suspected adverse drug reactions reported to the European medicines agency: Implications for pharmacovigilance. Pediatr. Drugs 2014, 16, 309-319. [CrossRef]

32. Xu, R.; Wang, Q. Large-scale combining signals from both biomedical literature and the FDA Adverse Event Reporting System (FAERS) to improve post-marketing drug safety signal detection. BMC Bioinform. 2014, 15, 17. [CrossRef]

33. Montastruc, G.; Favreliere, S.; Sommet, A.; Pathak, A.; Lapeyre-Mestre, M.; Perault-Pochat, M.-C.; Montastruc, J.-L. French Association of Regional PharmacoVigilance Centres Drugs and dilated cardiomyopathies: A case/noncase study in the French PharmacoVigilance Database. Br. J. Clin. Pharmacol. 2010, 69, 287-294. [CrossRef]

34. Platt, R.; Wilson, M.; Chan, K.A.; Benner, J.S.; Marchibroda, J.; McClellan, M. The new sentinel network-improving the evidence of medical-product safety. N. Engl. J. Med. 2009, 361, 645-647. [CrossRef] [PubMed]

35. Trifiro, G.; Fourrier-Reglat, A.; Sturkenboom, M.C.J.M.; D'iacuteaz, A.C.; Van Der Lei, J. The EU-ADR project: Preliminary results and perspective. SHTI 2009, 148, 43-49. [CrossRef]

36. Dandala, B.; Joopudi, V.; Tsou, C.-H.; Liang, J.J.; Suryanarayanan, P. Extraction of information related to drug safety surveillance from electronic health record notes: Joint modeling of entities and relations using knowledge-aware neural attentive models. JMIR Med. Inform. 2020, 8, e18417. [CrossRef]

37. Davazdahemami, B.; Delen, D. A chronological pharmacovigilance network analytics approach for predicting adverse drug events. J. Am. Med. Inform. Assoc. 2018, 25, 1311-1321. [CrossRef]

38. Winnenburg, R.; Sorbello, A.; Ripple, A.; Harpaz, R.; Tonning, J.; Szarfman, A.; Francis, H.; Bodenreider, O. Leveraging MEDLINE indexing for pharmacovigilance - Inherent limitations and mitigation strategies. J. Biomed. Inform. 2015, 57, 425-435. [CrossRef] [PubMed]

39. Yang, C.C.; Yang, H. Mining heterogeneous networks with topological features constructed from patient-contributed content for pharmacovigilance. Artif. Intell. Med. 2018, 90, 42-52. [CrossRef]

40. McCarren, M.; Qiu, H.; Ziyadeh, N.; Jiang, R.; Wang, Y.; McAfee, A.T. Follow-up study of a pharmacovigilance signal. J. Clin. Psychopharmacol. 2012, 32, 743-749. [CrossRef]

41. Sun, A.P.; Kirby, B.; Black, C.; Helms, P.J.; Bennie, M.; McLay, J.S. Unplanned medication discontinuation as a potential pharmacovigilance signal: A nested young person cohort study. BMC Pharmacol. Toxicol. 2014, 15, 11. [CrossRef]

42. Dupuch, M.; Grabar, N. Semantic distance-based creation of clusters of pharmacovigilance terms and their evaluation. J. Biomed. Inform. 2015, 54, 174-185. [CrossRef]

43. Pacurariu, A.C.; Straus, S.M.; Arlett, P.; Van Der Lei, J.; Sturkenboom, M.C.; Coloma, P.M.; Trifirò, G.; Schuemie, M.J.; Gini, R.; Herings, R.; et al. Useful interplay between spontaneous ADR reports and electronic healthcare records in signal detection. Drug Saf. 2015, 38, 1201-1210. [CrossRef]

44. Usui, M.; Aramaki, E.; Iwao, T.; Wakamiya, S.; Sakamoto, T.; Mochizuki, M.; Mayer, M.A.; Aripin, K.N.B.N. Extraction and standardization of patient complaints from electronic medication histories for pharmacovigilance: Natural language processing analysis in japanese. JMIR Med. Inform. 2018, 6, e11021. [CrossRef] [PubMed]

45. Thompson, P.; Daikou, S.; Ueno, K.; Batista-Navarro, R.; Tsujii, J.; Ananiadou, S. Annotation and detection of drug effects in text for pharmacovigilance. J. Chemin 2018, 10, 37-37:33. [CrossRef] [PubMed]

46. Kiguba, R.; Ndagije, H.B.; Nambasa, V.; Bird, S.M. Adverse drug reaction onsets in Uganda's Vigibase ${ }^{\circledR}$ : Delayed international visibility, data quality and illustrative signal detection analyses. Pharm. Med. 2018, 32, 413-427. [CrossRef] [PubMed]

47. Ventola, C.L. Big data and pharmacovigilance: Data mining for adverse drug events and interactions. P T 2018, 43, 340-351. [PubMed]

48. Wang, C.-S.; Lin, P.-J.; Cheng, C.-L.; Tai, S.-H.; Yang, Y.-H.K.; Chiang, J.-H. Detecting potential adverse drug reactions using a deep neural network model. J. Med. Internet Res. 2019, 21, e11016. [CrossRef] 
49. Richesson, R.; Hume, S.; Tsuji, S.; Huang, M.; Liu, H.; Shah, N.; Jiang, G.; Tingay, K.; Lin, C.-H.; Kijsanayotin, B.; et al. Detecting and filtering immune-related adverse events signal based on text mining and observational health data sciences and informatics common data model: Framework development study. JMIR Med. Inform. 2020, 8, e17353. [CrossRef]

50. Wang, L.; Rastegar-Mojarad, M.; Liu, H.; Ji, Z.; Liu, S.; Liu, K.; Moon, S.; Shen, F.; Wang, Y.; Yao, L.; et al. Detecting pharmacovigilance signals combining electronic medical records with spontaneous reports: A case study of conventional disease-modifying antirheumatic drugs for rheumatoid arthritis. Front. Pharmacol. 2018, 9. [CrossRef]

51. Rho, M.J.; Kim, S.R.; Park, S.H.; Jang, K.S.; Park, B.J.; Hong, J.Y.; Choi, I.Y. Common data model for decision support system of adverse drug reaction to extract knowledge from multi-center database. Inf. Technol. Manag. 2015, 17, 57-66. [CrossRef]

52. Vilar, S.; Harpaz, R.; Santana, L.; Uriarte, E.; Friedman, C. Enhancing adverse drug event detection in electronic health records using molecular structure similarity: Application to pancreatitis. PLoS ONE 2012, 7, e41471. [CrossRef]

53. Coloma, P.M.; Avillach, P.; Sturkenboom, M.; Trifirò, G.; Salvo, F.; Schuemie, M.J.; Ferrajolo, C.; Pariente, A.; Fourrier-Réglat, A.; Molokhia, M.; et al. A reference standard for evaluation of methods for drug safety signal detection using electronic healthcare record databases. Drug Saf. 2013, 36, 13-23. [CrossRef]

54. Crepin, S.; Godet, B.; Carrier, P.; Villeneuve, C.; Merle, L.; Laroche, M.-L. Probable drug-induced liver injury associated with aliskiren: Case report and review of adverse event reports from pharmacovigilance databases. Am. J. Health Pharm. 2014, 71, 643-647. [CrossRef] [PubMed]

55. Benkirane, R.; Soulaymani-Bencheikh, R.; Khattabi, A.; Benabdallah, G.; Alj, L.; Sefiani, H.; Hedna, K.; Ouammi, L.; Olsson, S.; Pal, S.N. Assessment of a new instrument for detecting preventable adverse drug reactions. Drug Saf. 2014, 38, 383-393. [CrossRef] [PubMed]

56. Winnenburg, R.; Shah, N.H. Generalized enrichment analysis improves the detection of adverse drug events from the biomedical literature. BMC Bioinform. 2016, 17, 250. [CrossRef] [PubMed]

57. Batel-Marques, F.; Penedones, A.; Mendes, D.; Alves, C. A systematic review of observational studies evaluating costs of adverse drug reactions. Clin. Outcomes Res. 2016, 8, 413-426. [CrossRef] [PubMed]

58. Scalfaro, E.; Streefkerk, H.J.; Merz, M.; Meier, C.; Lewis, D. Preliminary results of a novel algorithmic method aiming to support initial causality assessment of routine pharmacovigilance case reports for medication-induced liver injury: The PV-RUCAM. Drug Saf. 2017, 40, 715-727. [CrossRef]

59. Caster, O.; Dietrich, J.; Kürzinger, M.-L.; Lerch, M.; Maskell, S.; Norén, G.N.; Tcherny-Lessenot, S.; Vroman, B.; Wisniewski, A.; Van Stekelenborg, J. Assessment of the utility of social media for broad-ranging statistical signal detection in pharmacovigilance: Results from the WEB-RADR project. Drug Saf. 2018, 41, 1355-1369. [CrossRef]

60. Oosterhuis, I.; Zweers, P.; Rümke, H.; Muller-Hansma, A.; Van Puijenbroek, E.P. A tailor-made approach for causality assessment for ADR reports on drugs and vaccines. Pharmacoepidemiol. Drug Saf. 2019, 28, 544-550. [CrossRef]

61. Lee, S.; Han, J.; Park, R.W.; Kim, G.J.; Rim, J.H.; Cho, J.; Lee, K.H.; Lee, J.; Kim, S.; Kim, J.H. Development of a controlled vocabulary-based adverse drug reaction signal dictionary for multicenter electronic health record-based pharmacovigilance. Drug Saf. 2019, 42, 657-670. [CrossRef]

62. Blake, K.V.; Prilla, S.; Accadebled, S.; Guimier, M.; Biscaro, M.; Persson, I.; Arlett, P.; Blackburn, S.; Fitt, H. European Medicines Agency review of post-authorisation studies with implications for the European Network of Centres for Pharmacoepidemiology and Pharmacovigilance. Pharmacoepidemiol. Drug Saf. 2011, 20, 1021-1029. [CrossRef]

63. Ruggiero, S.; Rafaniello, C.; Rossi, F.; Capuano, A.; Bravaccio, C.; Grimaldi, G.; Granato, R.; Pascotto, A.; Sportiello, L.; Parretta, E.; et al. Safety of attention-deficit/Hyperactivity disorder medications in children: An intensive pharmacosurveillance monitoring study. J. Child Adolesc. Psychopharmacol. 2012, 22, 415-422. [CrossRef]

64. Härmark, L.; Alberts, S.; Van Puijenbroek, E.; Denig, P.; Van Grootheest, K. Representativeness of diabetes patients participating in a web-based adverse drug reaction monitoring system. Pharmacoepidemiol. Drug Saf. 2012, 22, 250-255. [CrossRef] [PubMed]

65. Liu, M.; Hinz, E.R.M.; Matheny, M.E.; Denny, J.C.; Schildcrout, J.S.; A. Miller, R.; Xu, H. Comparative analysis of pharmacovigilance methods in the detection of adverse drug reactions using electronic medical records. J. Am. Med. Inform. Assoc. 2013, 20, 420-426. [CrossRef]

66. Pal, S.N.; Olsson, S.; Brown, E.G. The monitoring medicines project: A multinational pharmacovigilance and public health project. Drug Saf. 2015, 38, 319-328. [CrossRef]

67. Layton, D.; Shakir, S.A.W. Specialist cohort event monitoring studies: A new study method for risk management in pharmacovigilance. Drug Saf. 2015, 38, 153-163. [CrossRef] [PubMed]

68. Bahk, C.Y.; Goshgarian, M.; Donahue, K.; Freifeld, C.C.; Menone, C.M.; Pierce, C.E.; Rodriguez, H.; Brownstein, J.S.; Furberg, R.; Dasgupta, N. Increasing patient engagement in pharmacovigilance through online community outreach and mobile reporting applications: An analysis of adverse event reporting for the essure device in the US. Pharm. Med. 2015, 29, 331-340. [CrossRef] [PubMed]

69. Sarker, A.; Ginn, R.; Nikfarjam, A.; O'Connor, K.; Smith, K.; Jayaraman, S.; Upadhaya, T.; Gonzalez, G. Utilizing social media data for pharmacovigilance: A review. J. Biomed. Inform. 2015, 54, 202-212. [CrossRef] [PubMed]

70. Pierce, C.E.; Bouri, K.; Dasgupta, N.; Pamer, C.; Proestel, S.; Rodriguez, H.W.; Van Le, H.; Freifeld, C.C.; Brownstein, J.S.; Walderhaug, M.; et al. Evaluation of facebook and Twitter monitoring to detect safety signals for medical products: An analysis of recent FDA safety alerts. Drug Saf. 2017, 40, 317-331. [CrossRef] 
71. Irving, E.; Bor, R.V.D.; Welsing, P.; Walsh, V.; Alfonso-Cristancho, R.; Harvey, C.; Garman, N.; Grobbee, D.E. Series: Pragmatic trials and real world evidence: Paper 7. Safety, quality and monitoring. J. Clin. Epidemiol. 2017, 91, 6-12. [CrossRef]

72. Simbrich, A.; for the REGIMS Investigators; Thibaut, J.; Khil, L.; Maximov, S.; Wiendl, H.; Berger, K. Chances and challenges of registry-based pharmacovigilance in multiple sclerosis: Lessons learnt from the implementation of the multicenter regims registry. Drug Saf. 2021, 44, 7-15. [CrossRef] [PubMed]

73. Ali, S.; Moinuddin, K.; Al-Aqqad, A.Q.; Salem, S.O.; Al-Dossari, M.A.; Ananzeh, A.M.; Bin Baqar, J. Knowledge and attitude of health-care professionals toward adverse drug reactions reporting at King Saud Medical City. J. Pharm. Bioallied Sci. 2018, 10, 29. [CrossRef]

74. Arulappen, A.L.; Danial, M.; Sulaiman, S.A.S. Evaluation of reported adverse drug reactions in antibiotic usage: A retrospective study from a tertiary care hospital, Malaysia. Front. Pharmacol. 2018, 9, 809. [CrossRef] [PubMed] 